\title{
O anel de Sarah Hirsch
}

\section{Representações do Holocausto em "Incident at Vichy"*}

Resenha de MILLER, Arthur. Incident at Vichy: A Play. New York: Penguin Books, 1985.

\section{Rodrigo Medina Zagni**}

No sonho havia dois grupos em um corredor escuro, acinzentado e limpo tal qual um

hospital. Um dos grupos caminhava comigo e ensinava-Ihes algo. Em determinado momento, a monitora do outro grupo trouxe-a até mim, dizendo que logo morreria. Seus olhos negros como a noite me fitavam e seu brilho denunciava o estado febril. Seu cabelo

igualmente negro, preso, liso, deixava à mostra as curvas suaves de seu pálido rosto, gravemente doentio apesar de jovem, mas ainda assim a mulher mais bela que já vi! Seu vestido era preto com flores brancas, de seda ou cetim. Sabia que logo morreria e foi então que apontei sua origem: “- Você é judeu-polonesa”. Ela respondeu afirmativamente com a cabeça e disse-me seu nome, que nunca mais lembrei apesar de sua voz ainda ecoar em minha mente.**

"Many times I used to ask my friends - if you love your country why is it necessary to hate other countries? To be a good German why must you despise everything that is not German? Until I realized the answer. They do these things not because they are German but because they are nothing. It is the halmark of the age - the less you exist the more important it is to make a clear impression. I can see them discussing it as a kind of ... truthfulness. After all, what is self-restraint but hypocrisy? If you despise Jews the most honest thing is to burn them up. And the fact that it costs money, and uses up trains and

\footnotetext{
* Miller, Arthur. Incident at Vichy, A Play; New York: Penguin Books, 1985. A peça foi representada pela primeira vez no dia 3 de dezembro de 1964 no ANTA - Washington Square Theatre, em New York; dirigida por Harold Clurman para o Repertory Theatre of Lincoln Center, para o Performing Arts.

** Docente do curso de Relações Internacionais da Universidade Federal de São Paulo (UNIFESP), é coordenador do Grupo de Pesquisa "Conflitos armados, massacres e genocídios na era contemporânea" (UNIFESP/CNPq). Historiador graduado pela Faculdade de Filosofia, Letras e Ciências Humanas da Universidade de São Paulo; doutorou-se pelo Programa de Pós-Graduação em Integração da América Latina da USP.
} 
personnel - this only guarantees the integrity, the purity, the existence of their feelings. .." Arthur Miller****

No dia 9 de maio de 1940 é posto em prática o Plano Manstein. Forças blindadas, panzers e a Luftwaffe, com seus Stukas (Junkers-87), aeronaves de caça e regimentos de paraquedistas cortam ao meio os exércitos aliados isolando as 10 divisões do General Lord Gort ${ }^{1}$, entrincheiradas no Norte da França, do Exército francês, com um efetivo que ali superava um milhão de homens na retaguarda e na linha Maginot, por onde os invasores nazistas, nos arredores de Sedan, desencadearam a invasão se espalhando em poucas horas por todo o território francês.

Na madrugada do dia 10, mais de 3 mil aviões bombardeiros decolam de aeroportos no norte da Alemanha com destino à França, Holanda e Bélgica. De forma sincronizada, blindados de 80 toneladas, lança-chamas e colunas motorizadas que haviam partido pelo norte atravessam a Floresta das Ardenas tomando o território arrasado pelos Stukas. Com pouca resistência e muito rapidamente a Wehrmacht ocupa a Córsega, a Savóia e parte da Provence, incluindo a Cote d'Azur.

De 5 para 6 de junho Lord Gort, de Dunquerque, determina a retirada de todas as tropas britânicas da França, o que não foi ultimado com facilidade e, num esforço derradeiro, a Operação Dínamo, cujo início se deu no dia 26 de maio, resgatou 1.420 soldados ingleses no cargueiro Monas's Isle, pelo canal, sob ataques incessantes da Luftwaffe.

\section{A França caíra!}

A entrada da Wehrmacht em Paris, em 14 de junho daquele mesmo ano, e a bandeira do III Reich hasteada sobre a Torre Eiffel, marcaram a derrocada da soberania francesa tratorada pelo avanço nazistas e, naquele mesmo dia, o governo de Reynaud instalava-se em Bordeaux. Operava-se ali uma fissura: com a ocupação desvelou-se um país dividido entre colaboracionistas, militantes da resistência e espectadores passivos.

\footnotetext{
${ }^{* * *}$ A ABNT ainda não normatizou citações para sonhos.

${ }^{* * * *}$ MILLER, Arthur. Incident at Vichy: A Play. New York: Penguin Books, 1985, p. 38.

${ }^{1}$ Comandante da Força Expedicionária Britânica.
} 
Este é o palco escolhido por Arthur Miller em "Incident at Vichy": a França prostrada nos primeiros anos de domínio germânico, mais especificamente a França colaboracionista de Petàin e sua república de Vichy.

No ano de 1942, período em que se passa a peça, agentes nazistas estão instalados na administração das principais cidades, apesar de em Vichy a ocupação não ter revogado as leis francesas, pois contavam com o apoio de um governo que comungava com o nacional-socialismo. Era como se existissem duas Franças, a partir de dois governos: uma dominada pelos nazistas ou com governantes regionais coniventes, como em Vichy; e outra que resistia em Bordeaux.

Não só ao sul como em toda a França os nazistas transitavam nas ruas em meio à população local, frequentavam bares, restaurantes, circulavam acompanhados de belas francesas em parques e praças. Como exército invasor impunham um modelo de assimilação que levava em conta a densa carga histórica na qual o francês ocupara a condição de inimigo hereditário.

Invasores e população local coexistiam numa estranha aceitação que não sobrevivia aos limiares do superficial. A tensão cotidiana se manifestava num dramático silêncio, quebrado com violência quando os ocupantes se davam a violentar aqueles que eram considerados seu maior e mais perigoso inimigo biológico: os judeus; bem como seus inimigos políticos: os comunistas. A perseguição antissemita era murmurada em toda a Europa, na forma de imprecisas narrativas sobre as atrocidades perpetradas pelos nazistas, algo que parecia ainda fantasioso e ao mesmo tempo catastrófico: a existência de campos de trabalho forçado, o cotidiano dos guetos, o suplício nos trens da morte, o morticínio sistemático em câmaras de gás e as fornalhas que o mundo ainda não conhecia. Nada era certo até então e seria necessário somente a retomada da Europa pelos Aliados, em especial a libertação da Polônia pelos russos em 1945, para que o mundo se defrontasse com uma verdade inconcebível: o Holocausto.

Uma fração da tensão sentida nos ares de toda a Europa, que caminhava garbosamente e a largos passos para o precipício tragada pela política expansionista nazista, culminaria no silêncio do local de detenção descrito por Miller em "Incident at Vichy", rompido apenas pelos diálogos daqueles que aguardavam pelo incerto num pátio, sob as luzes de holofotes de vigilância. 
No palco onde se desenvolve a trama, um corredor à direita leva a uma porta de acesso à rua; enquanto na outra extremidade o pátio, podia-se ver uma edificação que mais parecia um escritório, de onde ecoavam sons de uma máquina de escrever em ritmado funcionamento.

Da mesma construção projetavam-se, no pátio, duas janelas, onde em uma delas era denunciada, pela sombra, uma silhueta vestindo quepe, sentada à frente da ruidosa máquina de escrever. Comunicando-o com o escritório, uma porta se abria diretamente para o pátio onde seis homens e um garoto de não mais que 15 anos esperavam sentados em um longo banco de madeira para serem interrogados, ao que parecia, por nazistas auxiliados pelos policiais de Vichy.

Os sons eram de uma repartição pública em plena atividade burocrática, numa estranha normalidade em meio à catástrofe da guerra. $\mathrm{O}$ trabalho metódico que envolvia a repartição era o de caçar e catalogar pessoas, tendo como alvo primordial os judeus, entre outras minorias sociais e dissidentes políticos, numa França cujo grosso da população se calava - por medo ou conveniência - diante da notória perseguição em curso.

O garoto que junto dos demais aguardava pelo incerto era notadamente judeu: mal podia esconder seu temor quanto mais sua origem - seu medo o denunciava; e era exatamente isso que o distinguia naquele lugar. Enquanto a maior parte dos detidos para averiguação dissimulava sua origem, comportamento que garantiria sua sobrevivência, o menino sequer podia escondê-la. Fora apanhado pela patrulha quando estava a caminho da loja de penhores para onde levaria o anel de casamento de sua mãe, Sarah Hirsch, na esperança de vendê-lo, pois nada tinham para comer e aquele era o último bem, com algum valor, do qual poderiam se desfazer.

As restrições nazistas aos judeus fizeram com que vários experimentassem a fome, no extremo a morte por inanição (comum dos guetos aos campos) por não conseguirem nenhum tipo de trabalho remunerado. O estímulo aos saques e fechamento de suas lojas, sua demissão do serviço público, escolas, faculdades, em quase todos os setores da vida social, levara-os a uma situação de extrema penúria.

Até mesmo as famílias ricas, acostumadas ao luxo, viram-se do dia para a noite pobres e, em menor tempo ainda, miseráveis, tendo que se desfazer dos pertences que os nazistas, por sorte, não haviam ainda roubado. O saque dos fascistas às coleções de arte, bibliotecas, joias de família, mobiliário raro, tapeçaria e até mesmo dentes de ouro levou os 
invasores a erigir criminosas fortunas pessoais, além de fundos secretos destinados à reconstrução da internacional nazista caso declinasse o Reich "de mil anos" idealizado por Hitler. Nesse período, houve aqueles que enriqueceram com o declínio das fortunas judaicas, até mesmo populações civis, beneficiando-se da compra de objetos de elevado valor a preços humilhantes para aqueles que deles se desfaziam, sem amoedar o valor simbólico embutido nos objetos, sua própria historicidade que os tornava, no mais das vezes, impagáveis.

Certos objetos detêm um valor simbólico ainda maior do que qualquer avaliação oportunista poderia amoedar, são receptáculos de memórias afetivas que, ao se perderem, levam consigo, para as brumas do tempo, o próprio tempo vivido. Um anel de casamento, como no caso do objeto escolhido por Sarah Hirsh para ser vendido e com isso proporcionar qualquer alimento para seus filhos, não é constituído apenas pelo metal em sua materialidade: carrega grafada em si a história de vidas que se entrelaçaram e de cuja origem outras vidas passaram a existir e delas depender.

Dada alegoria desvela que a memória foi um dos alvos provavelmente mais violentados pelos nazistas que, com isso, não são culpados por terem vilipendiado apenas a carne e ossos daqueles que sucumbiram fisicamente; estes, muito provavelmente, já haviam sido aniquilados em alma e espírito. Não só por aqueles que viram as Górgonas e não voltaram; mas pelos sobreviventes que pagam até hoje um alto preço pela tentativa sistemática dos perpetradores de apagamento total da memória de seu povo.

Ver os filhos famintos, de certo é um caso limite suficiente para se desfazer daquilo que consiste no fragmento de uma vida.

Contudo, o menino havia falhado em sua missão. Não pôde trocar vender o anel e, por sua vez, não pôde comprar o pão que alimentaria sua mãe e irmãos; o menino estava ali, inerte e amedrontado, a espera no frio pátio descrito por Miller. Quantos gélidos e sombrios pátios e quantos meninos de fato existiram em igual ou pior situação? Talvez fosse mais fácil analisar ficcionalmente a obra se o paralelo histórico não fosse tão real e ao mesmo tempo tão brutal. Quanta destruição, na pequeneza do cotidiano, foram produzidas pela grandeza das guerras? Certamente esta resenha não pode dar conta de elementos quantitativos, uma vez que os esforços de Miller se centram na caracterização da qualidade do aniquilamento que ali se produziu. 
É provável que o lugar descrito se tratasse de uma repartição policial, ou tão somente um prédio público; mas o que determina o ápice da tensão milleriana é o fato de os que ali esperavam, como o garoto que Miller sequer nomeou, não faziam a menor ideia do que ocorreria. Foram capturados nas ruas da cidade por patrulhas compostas por seus iguais em nacionalidade, detetives franceses da polícia local que apoiavam taticamente oficiais alemães; em especial um que, ao que tudo indicava, seria médico. Chamavam-no "professor" e vestia trajes civis.

Sabe-se que os oficiais com maior prestígio e possibilidade de ascensão na hierarquia da Wehrmacht eram os médicos, uma vez que a ideia de limpeza étnica, a partir das teses pseudocientíficas da Eugenia, impregnava não só o discurso nazifascista; mas era sistematizada numa ação devastadora sob a fecha de política de saúde pública, tencionando dizimar judeus de toda a Europa, de forma premeditada, cientificamente elaborada e perpetrada em escala industrial. Essa ação legitimada pelo discurso médico e aspirando a condição de disciplina acadêmica - na forma da Higiene Racial -, fazia parte de uma "medicina nazista" que buscava no "bacilo do judaísmo" o fator patológico de uma raça decadente que deveria ser sobreposta pela ariana, num processo evolutivo enaltecido pelo discurso do darwinismo social. Para a pseudociência nazista, o homem atentava contra as leis da natureza, contra a própria evolução, ao permitir a existência de judeus.

É o que faz do médico não apenas um estudioso, um acadêmico, um "professor"; mas dos mais letais combatentes nazistas à frente de uma epopeica luta de raças. Para os que ali aguardavam, tratava-se da autoridade incumbida de diagnosticar, entre eles, os elementos nocivos do judaísmo.

Enquanto esperavam, especulavam sobre sua detenção para interrogatório, percebendo que alguns eram liberados e outros sofriam um destino incerto. São exatamente as incertezas que vão se avolumando e se transformando nos principais protagonistas desse significativo fragmento do universo de milleriano; uma presença inquietante e invisível, mas que concentra os mais dramáticos pontos de tensão da peça.

Os que adentravam ao pequeno escritório pareciam ser interrogados; tudo era registrado pelas batidas intermitentes da máquina de escrever; depois dali não se via para onde iam. Seu destino poderia ser tanto a morte quanto a liberdade, e as sociedades europeias pareciam estar se acostumando e aceitando, em 1942, tais extremos. 
Rumores sobre campos de concentração e de trabalho forçado, trens com seus vagões apinhados de pessoas que se amontoavam rumando para a Polônia, sem serem seguidos por trens que levassem alimentos e regressando vazios ou trazendo apenas roupas: nada era certo e tudo fazia crer o pior. Havia somente rumores a respeito de trens conduzidos por poloneses, que cruzavam a França e nos quais era possível ouvir pessoas no interior dos vagões, trancadas pelo lado de fora. De qualquer forma eram, naqueles tempos, relatos distantes daqueles que viram as atrocidades, se opondo à resistência dos que não podiam acreditar que tamanha barbárie pudesse ser real: “... beyond any belief'? Preferiam acreditar que as leis raciais alemãs não se aplicariam ao território francês, em especial em Vichy.

Perceberam que de igual maneira alguns dos que ali estavam tiveram seu nariz, orelhas e boca sistematicamente medidos pelo "professor", em plena rua, quando ainda de sua detenção. O procedimento médico procurava até mesmo por circuncisões, obrigandoos para isso a arriar as calças, o que revelava a busca por judeus. O discurso médico nazista procurava, a partir de traços biotípicos comuns, como a predominância do nariz aquilino e outras especificidades, determinar uma distinção racial que em termos concretos jamais existiu, em relação principalmente aos arianos. A esse respeito e dando voz ao personagem Leduc, Miller afirma não se tratarem os judeus de "uma raça", conceito cuja falência já era sabida a esse tempo: “. . . They can look like anybody”3.

Apesar de as pesquisas perpetradas pelos médicos nazistas não terem determinado diferenciação alguma no sangue de judeus, o discurso da antropologia racial ou da sociologia genética foi comumente usado pelos nazistas para distingui-los:

Professor: ( . . ) I certainly would never mistake you [Major] for a Jew. Any more than you could mistake a pig for a horse. Science is not capricious, Major; my degree is in racial anthopology. In any case, we can certainly separate the gentiles by this kind of examination. ${ }^{4}$

Sob a alegação de que efetuavam uma simples checagem de documentos, alegavam os policiais franceses de que se tratava de uma inspeção rotineira, pois a praxe para escapar à perseguição antissemita era falsificar identidades alterando o nome que

\footnotetext{
${ }^{2}$ MILLER, Arthur. Op. cit. p. 38.

${ }^{3}$ Ibid. p. 26.

${ }^{4}$ Ibid. p. 41.
}

JUS HUMANUM - REVISTA ELETRÔNICA DE CIÊNCIAS JURÍDICAS E SOCIAIS DA UNIVERSIDADE CRUZEIRO DO SUL. São Paulo, v. 1, n. 3, jan./jun. 2014. 
pudesse identificar a origem judaica. Alterando seus nomes, escondendo suas origens, desfazendo-se compulsoriamente da memória coletiva de seu povo, tentavam com isso sobreviver; mas a um preço elevadíssimo em termos identitários, como expresso por "Monceau: ( . . . ) After all, you are trying to create an illusion; to make them believe you are who your papers say you are". 5

Para os que ali esperavam, fica claro que negar-se a crer que as atrocidades nazistas fossem verdadeiras era sintomático da afirmação de uma tentativa desesperada de sobrevivência. Era mais fácil crer que se tratava de uma simples rotina de checagem, cujo escopo seria o de identificar espiões inimigos e agentes opositores ao regime nazista, do que uma ação deliberada de caça aos judeus.

A incerteza que se agiganta como elemento central da trama rapidamente preenche o pequeno compartimento de espera e contamina sentimentos como o de culpa. Inocência ou culpa por ter nascido no seio de uma família judaica; a perseguição antissemita na Europa foi tão contumaz e presente na História do Ocidente que essa culpa infundada se instalou no ethos dos judeus que a carregaram penosamente por séculos se esquivando de incontáveis perseguições e vultosos poderes, submetidos às mais diversas formas de segregação e violência, da simbólica à física, como o extremo das práticas de tortura, desde aquelas perpetradas pela Igreja, por Torquemada e seus agentes da Inquisição ibérica inspirados pelo mito cristão do deicídio, até as técnicas de Himmler, cuja inspiração deita raízes no romantismo alemão e cujas técnicas serviram-se das modernas e industrializadas formas de morticínio.

Lebeau: ( . . . ) they keep saying such terrible things about us, and you can't answer. And after years and years of it, you ... I wouldn't say you believe it, but ... you do, a little. It's a funny thing...6

$(\ldots)$

Lebeau: ... You begin wishing you'd commited a crime, you know? Something definite. ${ }^{7}$

A dúvida dos personagens é tamanha que escondem uns dos outros, de início, sua origem judaica.

\footnotetext{
${ }^{5}$ Ibid. p. 30.

${ }_{7}^{6}$ Ibid. p. 50.

${ }^{7}$ Ibid. p. 3.
} 
O ápice da tensão milleriana, o sentimento de incerteza, ganha forma na espera. É como a vítima que ouvindo o ruído do projétil que não deflagra aguarda seu executor repor a munição de sua arma, para então desfechar o disparo fatal: não é o disparo que a aniquila, é a tensão da espera e a certeza inexorável da morte. É como a criança que tem o castigo anunciado pelo pai: é a espera que a consome, ela mesma constitui o castigo maior. A tensão beira o insuportável quando o "castigo" é desconhecido, quando há apenas rumores a seu respeito, quando não se sabe se haverá ou não disparo: nesses termos é preferível saber que ele acontecerá! Nesse caso, a espera é aliada à incerteza, que aniquila lentamente todos naquele pátio, consumindo-os a ponto de os nazistas no extremo poderem dar cabo apenas dos corpos, uma vez que as almas já estariam prostradas a espera do golpe final.

Esta condição é evidenciada por Miller não apenas nos diálogos, mas principalmente nos longos e intermináveis silêncios, onde espera e incerteza se concentram: nos insuportáveis momentos que sucedem o aparente desfecho dos diálogos. Há muito mais significados neles do que as palavras podem conter.

O único, dentre todos, que nada pôde esconder foi o menino. Não disse sequer seu nome, apenas o de sua mãe, e o nome Hirsch evidenciava sua origem judaica. De fato, nem precisaria dizê-lo: seu comportamento o denunciava.

A angústia que Miller aloca neste personagem, na minuciosa descrição de seus movimentos, desenha a imagem da mãe que lhe aguarda junto de seus irmãos famintos, elementos apenas referidos na trama mas que ganham forma na consciência dos expectadores.

Se reduzirmos a tensão milleriana da espera pelo incerto à situação vivida pelo menino, manifesta-se algo ainda pior do que o destino duvidoso do grupo. Sarah Hirsch aguardava não só o dinheiro ou os pães que alimentariam sua prole, quem sabe por mais um ou dois dias: aguardava parte de si mesma numa espera fadada a não ter fim. Seu destino seriam os campos, as câmaras de gás e as fornalhas; e o de Sarah, como o de tantas mães: a fome e a espera por um filho que jamais retornaria.

Não saber o paradeiro e o que ocorreu a um ente querido é incontáveis vezes pior do que a ciência de sua morte, visto que a morte, da qual resulta o sentimento de perda e de ausência, é sucedida e processada pelo luto e o luto é a forma com que a psique, por sua vez, processa a dor da perda, transformando-a em experiência vivida. Na incerteza não 
há luto e a dor não pode ser processada, segue a consumir a alma de seu portador. Ser consumido por tal natureza de dor tornou-se um fenômeno generalizado para os judeus que tiveram seus familiares arrancados do seio de sua família e rumaram para um destino incógnito, no qual a probabilidade maior era o inferno dos campos de onde pouquíssimos retornaram.

Ainda assim, a única preocupação aparente do menino não era com o seu destino, não eram os relatos incertos acerca da existência de campos de morte, não era sequer a possibilidade de sua morte: sua única preocupação aparente era a fome de sua mãe e de seus irmãos, e isso o moveu a suplicar a Von Berg, ao perceber que não se tratava de um judeu e que logo seria liberado, que levasse o anel de volta à Sarah, ao número 9 da Rua Charlot. Dessa forma, sua mãe teria o que penhorar e com isso poderia ainda comprar um pouco de comida. Se não estivesse ali parado, naquela sala de detenção, pelo menos naquele dia a fome de sua mãe e irmãos poderia ser vencida.

Enquanto pensa na sobrevivência de Sarah Hirsch e de seus irmãos, sem se preocupar com sua possível morte, os demais, diante do incerto, se agarram em qualquer chance de sobrevivência, até mesmo nas possibilidades de serem aproveitados como força de trabalho escrava para carregar pedras ou construir desvios em Marseille ${ }^{8}$. Dessa forma, negam-se a acreditar nas fornalhas ou nas câmaras de gás, imaginando que faziam parte dos planos de monopólio de controle alemão, que seriam imprescindíveis vivos na condição de escravos para a indústria de guerra hitlerista e que seu assassinato não seria, em termos lógicos, uma possibilidade.

Segundo o discurso de Lebeau, essa aceitabilidade geraria ainda uma espécie de contemplação ao modelo germânico de trabalho, fazendo menção à superação das graves crises do final da década de 1920 e do começo de 30 (argumento comum na "mitologia do nazismo"), decorrentes das imposições restritivas do Tratado de Versalhes e da ocupação aliada, que entre outros fatores desencadearam a greve dos mineiros e a gravíssima inflação de 1932, que num contexto global caótico resultante da crise de 1929 acentuou ainda mais a depressão econômica alemã.

O mesmo personagem atribui a superação ao "trabalho duro"; e a impressão que temos é que Miller ironiza essa relação de contemplação: “Lebeau: ( . . . ) Good God, don’t

${ }^{8}$ lbid. p. 15.

JUS HUMANUM - REVISTA ELETRÔNICA DE CIÊNCIAS JURÍDICAS E SOCIAIS DA UNIVERSIDADE CRUZEIRO DO SUL. São Paulo, v. 1, n. 3, jan./jun. 2014. 
you ever read history? Wherever a people starts to work hard, watch out, they're going to kill somebody". 9

O crescimento econômico alemão, sua ascendente industrialização armamentista aliada à escassez de matérias-primas na Alemanha, principalmente de ferro e petróleo, resultou no que Ratzel preconizara como a "Teoria do Espaço Vital" e que sofreria a rancorosa leitura hitleriana. A sobrevivência da nação germânica implicaria na anexação, por tratados ou pela força, de territórios que poderiam servir como fornecedores desses itens imprescindíveis para sua indústria de guerra. Ao final da análise o próprio Miller conclui pela voz de um de seus personagens: ". . . Hitler is the creation of the capitalist class". ${ }^{10}$

Nesse contexto, as principais nações industrializadas do período convergiram para alinhamentos semelhantes.

Contudo, outras motivações, além das econômicas, devem ser levadas em consideração no palco da guerra e são, da mesma forma, lembradas por Arthur Miller no diálogo entre Leduc e Bayard. O que talvez tenha marcado fundamentalmente a natureza da Segunda Guerra Mundial após a invasão da URSS, em junho de 1941, foi o conflito operado no plano ideológico e que já havia sido evidenciado pelo pacto Anti-Komitern, de 1936, quando a guerra declarada contra o comunismo foi previamente anunciada preconizando a traição do pacto Germano-Soviético cinco anos depois. A guerra políticoideológica transcende a macro-história e se instala no universo milleriano, no ambiente da pequena sala de detenção, nas relações que mantêm os personagens:

Leduc: Still, when Germany attacked us the Communists refused to support France. They pronounced it an imperialist war. Until the Nazis turned against Russia; then in one afternoon it all changed into a sacred battle against tyranny $(\ldots)$

Bayard: My friend, without the Red Army standing up to them right now you could forget France for a thousand years! $!^{11}$

Sabemos que Miller se posicionou contra os fascismos europeus e militou, com toda a carga de problemas que isso Ihe pudesse causar em tempos de Macarthismo, em prol do

\footnotetext{
9 lbid. p. 10.

${ }_{11}^{10}$ Ibid. p. 34.

${ }^{11}$ lbid. p. 30.
} 
comunismo internacional, segundo sua biografia ${ }^{12}$; identificando nesse trecho da obra 0 dúbio por trás das formas possíveis de coercibilidade e manipulação político-ideológica em um mundo que assiste sua pior guerra no mal fadado século $X X .^{13}$

Sobretudo ao encaminhar-se para o desfecho da peça, Miller evidencia que os "finais felizes" devem ser reservados para obras menos comprometidas com o estudo do espírito humano e de seu avassalador poder destrutivo, para aqueles que acreditam na dissimulada inocência humana, que na expectativa de concretização do igualitarismo liberal do século XVIII ou do sonho da revolução socialista do início do século XX acabou produzindo duas guerras mundiais ao longo de sua primeira metade, cujo cerne se encontra no imperialismo decorrente do próprio desenvolvimento capitalista.

Miller reduziu a tensão resultante da perseguição antissemita, do medo dos campos de concentração, das câmaras de gás e das fornalhas, a uma simples sala de espera. Reduziu a macro História das nações e suas sagas às micro relações, à ficcional história de um menino judeu que pura e simplesmente espera; personagem que pode ter passado desapercebido do público menos atento, tanto quanto por muitos nas ruas de Vichy ou em qualquer outro lugar na Europa ocupada entre 1939 e 1945.

E não há de fato um desfecho redentor para a trama: Sarah Hirsch não reencontra seu filho, a incerteza de seu destino o público leva consigo e a concebe no seu íntimo, nas imagens mais tétricas possíveis associadas ao Holocausto e que já nos são comuns por terem se tornado icônicas: Miller nos faz pensar, construir o destino de uma personagem que sequer aparece em cena e imaginamos, na sua ausência que se torna presença, sua fome e sofrimento; por empatia sentimos parte de sua angústia e a incerteza que sobre ela se abate ao longo da peça: Sarah Hirsch.

\footnotetext{
${ }^{12}$ Cronologia baseada em pesquisada feita por Susan Haedicke: Arthur Miller ataca Ezra Pound em virtude de suas atividades pró-fascistas (1945); torna-se ativista pró-comunista e antifascista (1947); escreve várias peças criticando o Machartysmo, dentre as quais a principal: The Crucible; tem seu passaporte negado pelo Departamento de Estado para a montagem de The Crucible em Bruxelas em virtude de seu suporte ao movimento comunista (1954); apesar de ser delatado, nega-se a fornecer nomes de freqüentadores dos encontros organizados por comunistas ao Comitê de Atividades Anti-Americanas (1956); é acusado pelo crime de desprezar o Congresso americano se recusando a declinar nomes de comunistas (1957), sendo inocentado pela Corte de Apelamento dos EUA (1958); e finalmente autor da obra In Russia, ilustrado por fotografias de Inge Morath, sua terceira esposa (1969).

${ }^{13}$ É interessante o caso russo ter sido citado por Miller, pois a traição do pacto se dá exatamente um ano após a invasão da França.
} 
O garoto dá o anel a Von Berg, cuja missão é levá-lo de volta à Sarah. Sabemos que o anel por sua vez é dado à Leduc, junto de sua liberdade, ao preço da vida de Von Berg, pois essa era a pena àqueles que ajudavam judeus: o enforcamento. Leduc, ao receber $o$ anel sabia que aquele não-judeu que lhe dera a dádiva da vida certamente morreria.

E Sarah, que não vemos, segue esperando...

As luzes se apagam, o pano cai sobre o palco e a peça chega ao fim.

Esse é apenas um dos fragmentos do universo milleriano, minúsculo mas central neste ensaio. A narrativa secundária sobre o anel de Sarah Hirsch tem como protagonistas: a fome, a miséria, o desespero, a morte, a perseguição, a humilhação, a desarticulação do núcleo familiar, as destruição das teias de sociabilidade, os campos de concentração de judeus durante a Segunda Guerra Mundial, a incerteza e a espera por um filho que jamais retornará; todos decorrentes da intolerância de um século, da mecanização das sociedades humanas e do mal encarnado na ausência total e psicótica de empatia, decorrente do processo de coisificação da condição humana que insistimos em chamar de progresso, sem entendermos que o termo comumente leva a uma bifurcação: progresso técnico e progresso humano.

Devemos nos indagar: em que momento o atores sociais deste que foi um dos mais dramáticos processos históricos de uma "era de catástrofes", deixam de lado sua própria humanidade para se tornarem peças perfeitamente descartáveis em um tabuleiro.

Uma pista é a atribuição de números aos soldados em exércitos regulares.

Atribuíam-se números aos judeus, ao invés de nomes, promovendo-se assim sua desumanização. Não é a única estratégia para a produção da coisificação da condição humana; mas eliminando-os, resulta no extermínio sistematizado de caracteres, não de pessoas. Em uma sociedade em que pessoas são produzidas, circulam e são descartadas como bens de consumo de massa; resulta incoerente aceitar a coisificação da condição humana operada pela lógica do capitalismo e se horrorizar quando dado descarte se opera em escala industrial!

Bayard: ( . . ) What am I to them personaly? Do they know me ${ }^{14}$ $(\ldots)$

${ }^{14}$ MILLER, Arthur. Op. cit. p. 31. 
Are you telling me that history is a question of "certain people"? Are we sitting here because we are "certain people"? Is any of us an individual to them? . . ${ }^{15}$

A resposta mais plausível, se é que isso é possível, é a de que a impessoalidade característica do Holocausto é que o tornou possível.

Não é difícil entender o ceticismo com que os judeus de Vichy, como aqueles representados no universo milleriano, se negavam a aceitar a possibilidade de serem mortos sistematicamente, como os rumores sobre os campos davam conta e pior, com o aval de uma das populações mais cultas da Europa.

Monceau: ( . . . ) they were picking up Jews in Germany for years before the war, they've been doing it in Paris since they came in - are you telling me all those people are dead? Is that really conceivable to you? War is war, but you still have to keep a certain sense of proportion. I mean Germans are still people. ${ }^{16}$

Monceau não poderia imaginar que a Segunda Guerra Mundial teria como uma de suas mais acentuadas características exatamente a falta do senso de proporção citada. A desumanização, que aqui já fora mencionada, possibilitou o extermínio de judeus exatamente porque os nazistas tornaram-se incapazes de ver suas vítimas como pessoas. Os próprios nazistas haviam sido, desde sua juventude, submetidos a processos desumanizadores, como uma educação militarizada que ensinava primordialmente a odiar.

Os filmes de propaganda hitlerista, principalmente os de Nuremberg ${ }^{17}$, mostram os soldados alemães compondo um bloco único, vindos de todas as partes da Alemanha, não importasse qual, eram parte do mesmo corpo: dissolvidos como indivíduos na totalidade do corpo social, cuja "cabeça" seria o Führer. Ali não havia pessoas, mas componentes desumanizados de uma gigantesca engrenagem.

Vimos da mesma forma que não reconhecendo os judeus como pessoas, foi possível seu assassinato em massa, e Miller denuncia claramente esse aspecto do Holocausto: "Major ( . . . ): The are no persons any more, don't you see that? There will never be persons again ..."18

\footnotetext{
${ }^{15}$ lbid. p. 33.

${ }^{16}$ Ibid. p. 19.

17 TRIUMPH DES WILLENS. Direção: Leni Riefenstahl. Produção: Leni Riefenstahl. Roteiro: Leni Riefenstahl. [S.I.]: Continental Home Vídeo, 1936. 1 DVD (110 min.), son., preto e branco.

${ }^{18}$ MILLER, Arthur. Op. cit. p. 54.
} 
Monceau pensa uma lógica alemã que o levasse à conclusão de que o Holocausto nunca aconteceria: "Monceau: But what good are dead Jews to them? They want free labor. It's senseless. You can say whatever you like, but the Germans are not illogical; there's no conceivable advantage for them in such a thing." ${ }^{19}$

O fato é que não há lógica que conceba a "solução final". Não há tática que explique o extermínio de seis milhões de seres humanos, de pessoas, que tinham nome e memória: não eram apenas números.

Buscar uma explicação plausível para tamanha catástrofe é infrutífero como qualquer outra tentativa de compreender aquilo que não se pode, por meio lógico, calcular.

Por outro lado persiste o enigma proposto por Miller, por meio de Von Berg, sobre a população alemã: “. . . Can people with respect for art go about hounding Jews? Making a prision of Europe, pushing themselves forward as a race of policemen and brutes? Is that possible for artistic people?"20

Não tentamos responder estas questões nessa breve resenha, basta abstrairmos daí dois fatores: alemães e nazistas de forma alguma designam obrigatoriamente o mesmo indivíduo. Até mesmo o oficialato da Wehrmacht se rebelou contra Hitler antes e durante a guerra, no caso do expurgo da $\mathrm{SA}^{21}$ e do atentado à bomba de Berlim ${ }^{22}$.

Busquemos então a resposta no discurso do mesmo personagem, quando afirma que ". . . Art is perhaps no defense against this"23.

Sabemos que a arte era vastamente explorada nos filmes publicitários do III Reich, conclamando-se o resgate do estilo neoclássico contra o expressionismo, o cubismo e outras vanguardas tidas pelos nazistas como "arte degenerada". Nos mesmos filmes as pinturas expressionistas eram dispostas ao lado de fotografias de dementes e deficientes físicos, fazendo-se uma alusão à "raça degenerada" e ao discurso médico de purificação

\footnotetext{
${ }^{19}$ lbid. p. 37.

20 lbid. p. 24.

21 "A noite dos longos punhais": em decorrência das críticas da ala radical do próprio Partido Nazista, liderada por Ernest Röhm, acusado por Hitler de conspirar para destituí-lo do poder e aos 30 de junho de 1934, junto de outros pelo menos cem componentes do Partido Nazista, foram caçados e assassinados pela Polícia Secreta alemã.

${ }^{22}$ Perpetrado por Von Stauffenberg e executado aos 20 de julho de 1944, com o objetivo principal de matar Adolf Hitler.

${ }^{23}$ MILLER, Arthur. Op. cit. p. 24.
} 
racial $^{24}$. A cruzada da arte neoclássica contra o expressionismo deveria estar imbuída do mesmo sentido estético que a luta entre a raça ariana contra a semita, para Hitler, seus comandados e para grande parte da população alemã. A estética nazista encontrava sua fundamentação na arte, quando eleito o "belo", servindo-se ao extermínio de todo o resto.

Seria extremo reducionismo dizer que a perseguição que os nazistas perpetraram contra os judeus, processo histórico eivado de especificidades, não encontra paralelos em movimentos persecutórios que vitimaram incontáveis povos desde a antiguidade até o tempo presente.

Todos os povos têm os seus "judeus", e até mesmo os judeus tiveram seus subjugados durante a História, e isso não implica que uma intolerância possa justificar outra. Trata-se de como ver o outro. Até mesmo os expansionismos econômicos e as rivalidades políticas são acentuadas ou desencadeadas pelo olhar etnocêntrico.

Leduc: ( . . . ) Each man has his Jew; it is the other. And the Jews have their Jews. And now, now above all, you must see that you have yours - the man whose death leaves you relieved that you are not him, despise your decency. And that is why there is nothing and will be nothing ... 25

$(\ldots)$

Monceau: ( . . . ) The Russian condemn the middle class, the English have condemned the Indians, Africans, and nobody else they could lay their hands on, the French, the Italians ... every nation condemned somebody because of his race, includding the Americans and what they do to Negroes. The vast majority of mankind is condemned because of its race. What do you advise all these people - suicide? ${ }^{26}$

O que concluímos derradeiramente não se trata de nada novo, mas algo que deve ser constantemente reafirmado, dito à exaustão: não há povos inferiores, há olhares equivocados, anacrônicos, etnocêntricos, descabidos. Os fatores que permitem sua dominação e até mesmo seu extermínio são outros, externos à identidade étnica. O motor que move as máquinas de guerra, as fábricas que industrializam o extermínio, que fazem da ciência o fator desagregador e até mesmo da medicina um instrumento letal, é alimentado pelo combustível da intolerância.

${ }^{24}$ ARCHTEKTUR DES UNTERGANGS. Direção: Peter Cohen. Produção: Peter Cohen. Roteiro: Peter Cohen. Interpretes: Bruno Ganz (narrado por). [S.I.]: Poj Filmproduktion AB Filmnstitutet, Sveriges Television Kanal 1, Sandrew Film \& Teater AB Zeigen, 1999. 1 DVD (110 min.), son.; color.

${ }^{25}$ MILLER, Arthur. Op. cit. p. 66.

${ }^{26}$ Ibid. p. 51.

JUS HUMANUM - REVISTA ELETRÔNICA DE CIÊNCIAS JURÍDICAS E SOCIAIS DA UNIVERSIDADE CRUZEIRO DO SUL. São Paulo, v. 1, n. 3, jan./jun. 2014. 
"None of us is alone. We're members of history. Some of us don't know it, but you'd better learn it for your own preservation. "27

Arthur Miller

\section{Bibliografia:}

FELDMAN, Alexandre. "Representação da Shoá na literatura hebraica"; ensaio apresentado ao curso de extensão cultural "Elementos bíblicos e a representação do holocausto nas obras de Arthur Miller", Faculdade de Filosofia, Letras e Ciências Humanas da Universidade de São Paulo, São Paulo, 2004.

FOSTER, Arnold. Mundo em Guerra. Rio de Janeiro: Editora Record, 1973.

MILLER, Arthur. A View from the Bridge \& All My Sons. New York: Penguin Books, 1961. . After The Fall. New York: Penguin Books, 1964. . The creation of the world and other business. s/l: s/ed., 1973. . Arthur Miller's adaptation of "An enemy of the people" by Henrik Ibsen. New York: Penguin Books, 1979. . Incident at Vichy: A Play. New York: Penguin Books, 1985. . Broken Glass: A Play in Two Acts. New York: Penguin Books, 1994. . As Bruxas de Salem. Rio de Janeiro: Ediouro Publicações S.A., 1997.

POLIAKOV, Leon. A Europa suicida: 1870-1933. São Paulo: Editora Perspectiva, 1977 TOLAND, John. Adolf Hitler. Rio de Janeiro: Francisco Alves, 1978.

\section{Filmografia:}

ARCHTEKTUR DES UNTERGANGS. Direção: Peter Cohen. Produção: Peter Cohen. Roteiro: Peter Cohen. Interpretes: Bruno Ganz (narrado por). [S.I.]: Poj Filmproduktion AB Filmnstitutet, Sveriges Television Kanal 1, Sandrew Film \& Teater AB Zeigen, 1999. 1 DVD (110 min.), son.; color.

TRIUMPH DES WILLENS. Direção: Leni Riefenstahl. Produção: Leni Riefenstahl. Roteiro: Leni Riefenstahl. [S.I.]: Continental Home Vídeo, 1936. 1 DVD (110 min.), son., preto e branco.

${ }^{27}$ Ibid. p. 31.

JUS HUMANUM - REVISTA ELETRÔNICA DE CIÊNCIAS JURÍDICAS E SOCIAIS DA UNIVERSIDADE CRUZEIRO DO SUL. São Paulo, v. 1, n. 3, jan./jun. 2014. 